\title{
Water extract of Clinacanthus nutans leaves exhibits in vitro, ex vivo and in vivo anti- angiogenic activities in endothelial cell via suppression of cell proliferation
}

\author{
Chin Theng Ng ${ }^{1,7}$, Lai Yen Fong ${ }^{2}$, Jun Jie Tan ${ }^{3}$, Nor Fadilah Rajab ${ }^{4}$, Faridah Abas ${ }^{5}$, Khozirah Shaari ${ }^{6}$, \\ Kok Meng Chan ${ }^{4}$, Fariza Juliana ${ }^{4}$ and Yoke Keong Yong ${ }^{7 *}$
}

\begin{abstract}
Background: Clinacanthus nutans (Burm. f.) Lindau. has traditionally been using in South East Asia countries to manage cancer. However, scientific evidence is generally lacking to support this traditional claim. This study aims to investigate the in vitro, ex-vivo and in vivo effects of $C$. nutans extracts on angiogenesis.

Methods: C. nutans leaves was extracted with $50-100 \%$ ethanol or deionised water at 1\% (W/V). Human umbilical veins endothelial cell (HUVEC) proliferation was examined using MTT assay. The in vitro anti-angiogenic effects of $C$. nutans were assessed using wound scratch, tube formation and transwell migration assays. The VEGF levels secreted by human oral squamous cell carcinoma (HSC-4) cell and HUVEC permeability were also measured. Besides, the rat aortic ring and chick embryo chorioallantoic membrane (CAM) assays, representing ex vivo and in vivo models, respectively, were performed.

Results: The MTT assay revealed that water extract of $C$. nutans leaves exhibited the highest activity, compared to the ethanol extracts. Therefore, the water extract was chosen for subsequent experiments. C. nutans leaf extract significantly suppressed endothelial cell proliferation and migration in both absence and presence of VEGF. However, the water extract failed to suppress HUVEC transmigration, differentiation and permeability. C. nutans water extract also did not suppress HSC-4 cell-induced VEGF production. Importantly, C. nutans water extract significantly abolished the sprouting of vessels in aortic rings as well as in chick embryo CAM.

Conclusion: In conclusion, these findings reveal potential anti-angiogenic effects of $C$. nutans, providing new evidence for its potential application as an anti-angiogenic agent.
\end{abstract}

Keywords: Clinacanthus nutans, Acanthaceae, Angiogenesis, Chick embryo choriollantoic membrane, Aortic ring

\section{Background}

Angiogenesis is the main contributor to the transition of pre-invasive and dormant tumour cells to a more invasive and malignant cells, through establishing additional blood vessel network from pre-existing vasculature to enable more efficient oxygen and nutrient delivery for growth. Such pathologic event is orchestrated by overexpression of vascular endothelial growth factor (VEGF) secreted by

\footnotetext{
* Correspondence: yoke_keong@upm.edu.my

7 Department of Human Anatomy, Faculty of Medicine and Health Sciences,

Universiti Putra Malaysia, 43400 UPM Serdang, Selangor, Malaysia

Full list of author information is available at the end of the article
}

tumour cells, the known factor that promotes endothelial cell proliferation, invasion, migration and capillary tube formation [1]. Hence, inhibition of tumour angiogenesis by targeting VEGF pathway has emerged as an important strategy in combating cancers [2].

However, the new blood vessels formed are unlike normal blood vessels; they exhibit increased permeability, and cause diminished blood flow and create hypoxic microenvironment within the tumour [3]. To date, not more than 15 identified anti-cancer drugs that target tumour angiogenesis are granted approval from US Food and Drug Administration. In addition to undesirable side

(c) The Author(s). 2018 Open Access This article is distributed under the terms of the Creative Commons Attribution 4.0 International License (http://creativecommons.org/licenses/by/4.0/) which permits unrestricted use, distribution, and reproduction in any medium, provided you give appropriate credit to the original author(s) and the source, provide a link to the Creative Commons license, and indicate if changes were made. The Creative Commons Public Domain Dedication waiver (http://creativecommons.org/publicdomain/zero/1.0/) applies to the data made available in this article, unless otherwise stated. 
effects and low patient survival, those agents often couple with low therapeutic efficacy and high risk of drug resistance after long-term treatment, as reported in trials involving small cell lung cancer patients treated with bevacizumab and sunitinib [4]. The current anti-angiogenic drugs are single-target based agents which often could not achieve desired outcomes from inhibiting angiogenesis, mainly because of the redundancy in the angiogenic pathways.

Traditional plant extracts are source of multi-targeted therapeutic agents as they contain various medicinal phytochemicals. The production cost is usually low due to their abundance in nature. Plant extracts may also reduce the risk of adaptive resistance that is commonly seen in therapy with single agent [3]. Clinacanthus nutans (Burm. f.) Lindau. is locally known as Sabah Snake Grass, belonging to the Acanthaceae family. C. nutans has been used traditionally as a medicinal herb in tropical Asia to treat various diseases such as insect bites, diabetes mellitus, diuretics and fever [5]. Previous studies have reported that $C$. nutans possesses cytotoxicity [6], anti-proliferative, anti-oxidant [7] and anti-inflammatory [8] activities. Ethanol extract of $C$. nutans has been shown to impede hepatoma in mice through induction of apoptosis and enhancement of immune response [9]. Researchers have also demonstrated that $C$. nutans methanol extract induces human melanoma cell apoptosis [10]. Despite claims regarding the use of $C$. nutans in treating various cancers, the anti-angiogenic potential of $C$. nutans has never been carefully examined. Here we showed that $C$. nutans is a potential anti-cancer agent that possesses inhibitory effects on VEGF-mediated angiogenic events, based on in vitro findings using human umbilical vein endothelial cells (HUVECs), ex vivo test using rat aortic ring and in vivo investigation using chick embryo chorioallantoic membrane (CAM) assays.

\section{Methods}

\section{Chemicals and reagents}

HUVECs, EndoGRO culture media, human VEGF $_{165}$, Millicell cell culture inserts with pore size of $8.0 \mu \mathrm{m}$, in vitro vascular permeability assay kit and EndoGRO-LS complete culture media kit were purchased from Milipore. Growth factor-reduced matrigel was purchased from BD Bioscience. Human oral squamous cell carcinoma (HSC-4) cells and Dulbecco's Modified Eagle's Medium (DMEM) were purchased from American Type Culture Collection (ATCC). Human VEGF Quantikine ELISA kit was purchased from R\&D Systems. Suramin (purity $>$ 99\% by TLC) was purchased from Sigma-Aldrich.

\section{Plant material}

Whole plant of Clinacanthus nutans (Burm. f.) Lindau was harvested from the Sendayan Commodities Development Centre in Seremban, Negeri Sembilan, Malaysia. The plant was verified by Dr. Shamsul Khamis, botanist at Institute of Bioscience, Universiti Putra Malaysia. The specimen of $C$. nutans has been deposited at the herbarium of the Institute of Bioscience, Universiti Putra Malaysia (voucher number: SK 2883/15).

\section{C. nutans leaf extraction}

C. nutans leaf extracts were obtained from our previous work [11]. Briefly, the plant was harvested, cleaned with water, dried and separated into leaves and stems. The leaves were then dried at room temperature under the shade in a well-ventilated room and ground to fine powder. Next, the ground powder was extracted by sonicating in 50,70 , and $100 \%$ ethanol or deionised water at $1 \%(w / v)$ for $1 \mathrm{~h}$ without heating. The extraction was repeated thrice for each sample, followed by filtered-sterilization and vacuum evaporation to dry and freeze-dry the extracted samples prior to storing at $4{ }^{\circ} \mathrm{C}$ until further analysis.

\section{Cell culture}

HUVECs were purchased from Merck, Malaysia, and grown in T-25 cell culture flasks with EndoGRO culture media. HUVECs between passage three to six were used in the experiments. Human oral squamous cell carcinoma (HSC-4) cells from American Type Culture Collection (ATCC) were maintained in Dulbecco-modified Eagle Medium (DMEM) supplemented with 10\% FBS and $4 \mathrm{mM}$ L-glutamine. All the cells were incubated at $37{ }^{\circ} \mathrm{C}$ in an incubator with $95 \%$ humidified air and $5 \%$ $\mathrm{CO}_{2}$.

\section{Cell proliferation assay}

Cell proliferation assay was performed as described previously by Mosmann [12], with some modifications. HUVECs were plated onto 96-well plates at a cell density of $1.0 \times 10^{4}$ cells per well. After $24 \mathrm{~h}$, cells were treated with different $C$. nutans extracts and subsequently incubated for 24,48 and $72 \mathrm{~h}$ in separate well plates. After indicated times, $10 \mu \mathrm{l}$ of MTT $(5 \mathrm{mg} / \mathrm{ml}$ stock concentration) was added into each well and incubated in an incubator for additional $4 \mathrm{~h}$. Then, MTT solution was removed and the purple formazan was dissolved in $100 \mu \mathrm{l}$ of dimethyl sulfoxide (DMSO). The absorbance was measured using a microplate reader (Tecan M200 Infinite) at a wavelength of $570 \mathrm{~nm}$ with a reference wavelength of $650 \mathrm{~nm}$.

\section{Wound healing assay}

The assay was carried out according to Kavitha et al. [13] with some modifications. HUVECs were plated onto 6-well plates and allowed to grow until confluence. Then, a defined scratch gap was created using a 100 $200 \mu$ l-pipette tip. All detached/dead cells were removed by several washes with media. Then, cells were 
co-treated with human $\mathrm{VEGF}_{165}$ and C. nutans extracts. Images were captured at $40 \times$ magnification, at $0 \mathrm{~h}$ (baseline) and $12 \mathrm{~h}$ as soon as the gap in VEGF-treated groups was completely covered by cells, using an inverted microscope (Olympus CKX31). The cell migration was quantified using the formula: Initial wound distance minus final wound distance divided by two [13].

\section{Tube formation assay}

Tube formation method was performed according to Arnaoutova and Kleinman [14]. Briefly, growth factor-reduced Matrigel ${ }^{\mathrm{m}}$ was pipetted into pre-chilled 96-well plates and polymerized at $37{ }^{\circ} \mathrm{C}$ for $30 \mathrm{mins}$. HUVECs $\left(1.5 \times 10^{4}\right.$ cells per well $)$ were seeded onto the Matrigel-coated plates. C. nutans extract at 50 to $1000 \mu \mathrm{g} / \mathrm{ml}$ were added at plating. After $3 \mathrm{~h}$, the tubular structure was visualized and the images were captured using an inverted microscope at $40 \times$ magnification. The tube length was quantified using an Image $J$ with integrated angiogenesis analyser plugin (Gilles Carpentier, Faculté des Sciences et. Technolo-gie, Université Paris Est, Creteil Val de Marne, France).

\section{Transwell migration assay}

Transmigration of HUVECs was studied as described previously by Kavitha et al. [13] with slight modifications. Briefly, HUVECs $\left(3 \times 10^{4}\right.$ cells per well $)$ were cultured on Millicell cell culture inserts with pore size of $8.0 \mu \mathrm{m}$, and treated with 50 to $1000 \mu \mathrm{g} / \mathrm{ml} \mathrm{C}$. nutans extract dissolved in EndoGRO media supplemented with $0.5 \%$ FBS. Bottom wells were filled with $750 \mu$ of EndoGRO media containing $10 \mathrm{ng} / \mathrm{ml}$ human $\mathrm{VEGF}_{165}$ and extract similar to that of the inserts. After $6 \mathrm{~h}$, non-migrated cells on the insert membrane were removed by cotton swabs, and migrated cells were fixed with $4 \%$ paraformaldehyde and stained with $0.1 \%$ crystal violet. The dyes were extracted using 10\% acetic acid and the absorbance was measured by a microplate reader at $590 \mathrm{~nm}$.

\section{In vitro vascular permeability assay}

The in vitro vascular permeability assay was performed according to manufacturer's protocol. Briefly, HUVECs were grown to confluence on collagen-coated inserts. Next, the monolayers were treated with different concentrations of $C$. nutans extract. After $24 \mathrm{~h}$, FITC-dextran solution was added onto the cultured HUVEC monolayer for $20 \mathrm{~min}$, and the fluorescence intensity of FITC-dextran that crossed the cell layer were measured using Tecan Infinite M200 fluorescence plate reader at 485/530 $\mathrm{nm}$ (Excitation/Emission), as described previously by $\mathrm{Ng}$ et al. [15].

\section{VEGF levels}

HSC-4 cells were seeded onto 96-well plates at a cell density of $1 \times 10^{4}$ cells per well. Then, cells were treated with 50 to $1000 \mu \mathrm{g} / \mathrm{ml}$ of $C$. nutans extract for $72 \mathrm{~h}$. VEGF levels in HSC-4 were quantified using Human VEGF Quantikine ELISA kit. Absorbance were read at $450 \mathrm{~nm}$ and corrected to $570 \mathrm{~nm}$.

\section{Experimental animal}

Healthy male Spradue Dawley rats (aged 6-8 weeks old) from the Faculty of Medicine and Health Sciences, Universiti Putra Malaysia, were acclimatized for 7 days under standard environmental conditions. The rats were free access to standard laboratory chow and water ad libitum, and were kept in a room with $12 \mathrm{~h}$ day/night cycle.

\section{Ex-vivo aortic ring assay}

The animals were euthanatized by $\mathrm{CO}_{2}$ exposure and aortas were isolated from male Sprague Dawley rats (UPM/IACUC/AUP-R071/2015) according to Bellacen and Lewis [16]. Pre-chilled 48-well plates were filled with $150 \mu \mathrm{l}$ of Matrigel ${ }^{\mathrm{ma}}$ and allowed to polymerise for 30 mins at $37^{\circ} \mathrm{C}$. Rat aortas were rinsed with cold sterile phosphate-buffered saline and cut into $1 \mathrm{~mm}$-long cross sections. Aortic rings were placed on Matrigel and covered with an additional $150 \mu \mathrm{l}$ of Matrigel. The aortic rings were fed with $500 \mu \mathrm{l}$ of complete culture media, or supplemented with $C$. nutan at 50 to $1000 \mu \mathrm{g} / \mathrm{ml}$. The treatments were replaced daily. Growing sprouts, at day 8 , were photographed with an inverted microscope (Olympus), and the sprout length was analysed by Image J NIH software program.

\section{In vivo chick embryo chorioallantoic membrane (CAM) assay}

Fertilized chicken eggs were purchased from a poultry farm (Hing Hong Sdn. Bhd) and incubated in a $38{ }^{\circ} \mathrm{C}$ oven with $60 \%$ humidified air for $72 \mathrm{~h}$. The CAM assay was performed according to West et al. [17]. Briefly, the shell of eggs was gently cleaned and wiped with $70 \%$ ethanol. With caution, a small hole was created with an 18 -gauge needle on the narrow end of the eggs and $3 \mathrm{ml}$ of albumin was removed. The needle hole was then sealed with clear tapes. Subsequently, a small window was carefully created on the top-most surface of the eggshells. The windows were then covered by sterile paraf$\mathrm{ilm}$ and the eggs were placed back into the oven. After 8 days, 500,1000 and $2000 \mu \mathrm{g} / \mathrm{ml}$ of $C$. nutans were applied onto sterile filter disks and dried before grafting on the CAM. After that, the windows were sealed by a sterile parafilm and the eggs were placed back into the oven. After $48 \mathrm{~h}$, the CAMs were fixed with $4 \%$ paraformaldehyde at $4{ }^{\circ} \mathrm{C}$, overnight. Angiogenesis levels were 
determined by counting the number of vessels contacted to $C$. nutans disks.

\section{Statistical analysis}

The data were expressed as the mean \pm SEM. Statistical analysis was performed using IBM SPSS 20.0. One-way analysis of variance (ANOVA) followed by Tukey's test was used to compare means for the multiple groups. $p$ values less than $0.05(p<0.05)$ were considered to be statistically significant.

\section{Results}

\section{C. nutans water extract suppresses endothelial cell growth}

Extraction of C. nutans using 50, 70 and 100\% ethanol did not affect HUVEC viability regardless of its concentrations up to $100 \mu \mathrm{g} / \mathrm{ml}$. Such effect remains unaltered even with prolonged treatment time from 24 to $72 \mathrm{~h}$ (Fig. 1). On the contrary, 50 and $100 \mu \mathrm{g} / \mathrm{ml}$ of C. nutans in water extract showed significant reduction of HUVEC viability to $80.20 \pm 5.82$ and $79.33 \pm 4.81 \%$, respectively, after 48 and $72 \mathrm{~h}$ as compared to untreated control. At a lower $C$. nutans concentration of $25 \mu \mathrm{g} / \mathrm{ml}$, such significant difference was only observed after $72 \mathrm{~h}$ (Fig. 1). These data suggest that the water soluble compounds within the C. nutans water extract could suppress endothelial cell growth. We then tested the $C$. nutans water extract at higher concentrations ranging from 50 to $1000 \mu \mathrm{g} / \mathrm{ml}$ to see if the anti-proliferative effect can be seen within $24 \mathrm{~h}$ without causing significant cytotoxicity.
However, water extract of $C$. nutans neither suppressed HUVEC growth, nor caused cell death after 24 h (data not shown).

VEGF is the known driver of endothelial cell proliferation within tumour microenvironment condition [18]. To better mimic the pathologic conditions, we treated the HUVEC with the water extract of $C$. nutans in the presence of VEGF for 24, 48 and $72 \mathrm{~h}$. As expected, with increasing concentration of C. nutans from 50 to $1000 \mu \mathrm{g} / \mathrm{ml}$, the water extract significantly suppressed VEGF-induced HUVECs proliferation from $80.72 \pm 0.42 \%$ to $67.25 \pm 1.42 \%$ $(p<0.05)$ in $48 \mathrm{~h}$, and $78.37 \pm 2.09$ to $48.88 \pm 0.93 \%$ in $72 \mathrm{~h}$ $(p<0.05)$ as compared to VEGF alone (Fig. 2). These findings suggest the water extract could suppress endothelial growth in dose-dependent manner.

\section{C. nutans water extract suppresses endothelial cell migration}

Next, we examined the effects of ethanol and water extract of $C$. nutans on endothelial cell migration based on wound-healing assay. Again, no inhibitory effect was observed in ethanol extract-treated group. However, when HUVECs were treated with the $C$. nutans water extract with increasing concentrations from $12.5 \mu \mathrm{g} / \mathrm{ml}$ to $100 \mu \mathrm{g} / \mathrm{ml}$, the migration distance was reduced from $83.21 \pm 4.24 \%$ to $81.50 \pm 5.29 \%(p<0.05)$ (Fig. 3$)$.

In contrast, HUVECs were also found less migratory when tested with $C$. nutans water extracts at high concentrations from $50 \mu \mathrm{g} / \mathrm{ml}$ to $1000 \mu \mathrm{g} / \mathrm{ml}$, with the measured cell migration distance value significantly reduced

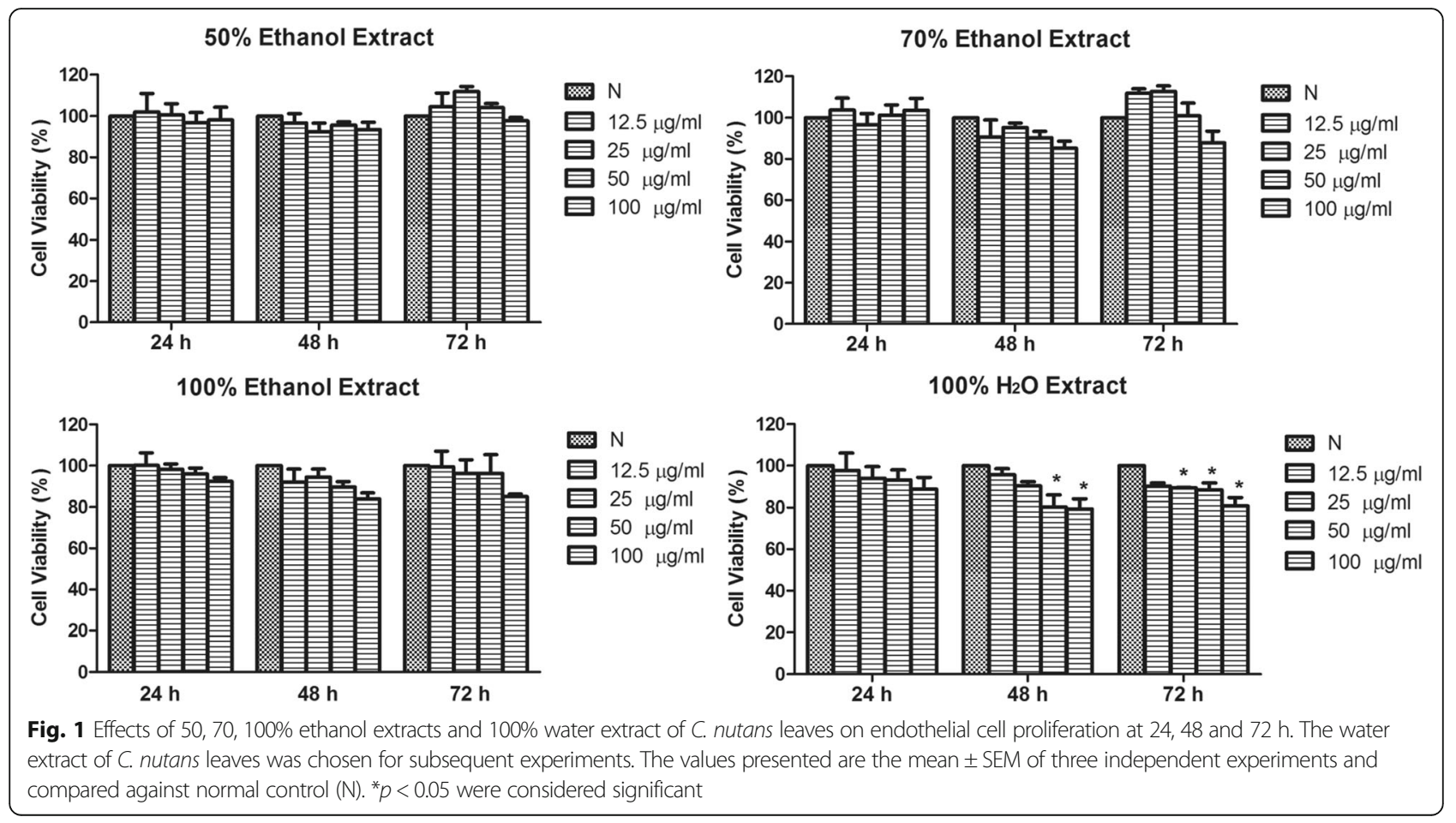




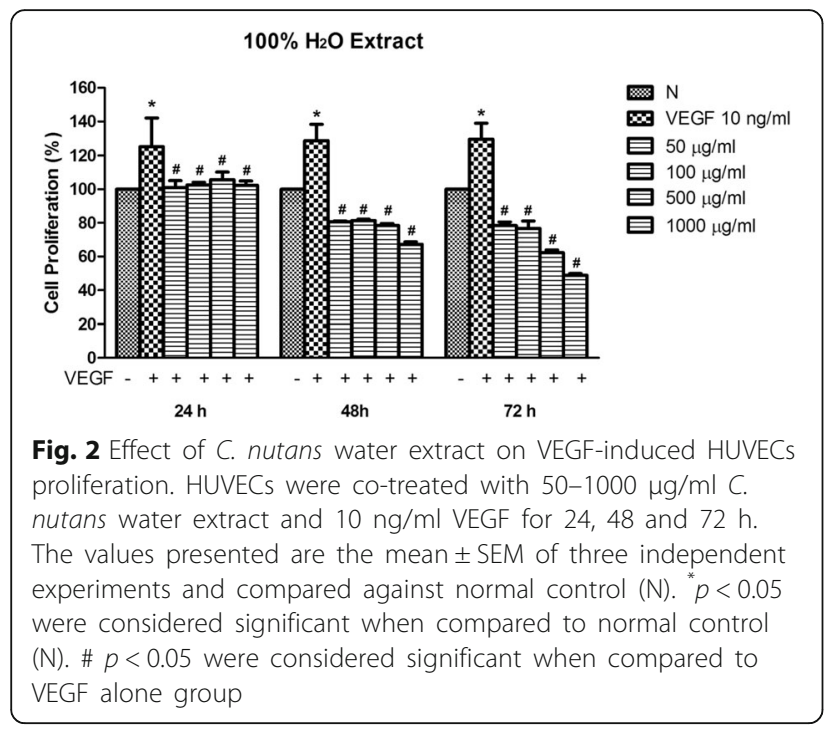

from $82.04 \pm 0.92 \%$ to $77.16 \pm 4.33 \%(p<0.05)$ (Fig. 4$)$ in the presence of VEGF. These results suggest that water extract of $C$. nutans disrupts VEGF-stimulated HUVEC migration.

\section{C. nutans water extract does not suppress VEGF-induced HUVECs transmigration}

Endothelial cell migration is known to be driven by VEGF gradient [19]. A Boyden chamber assay, which creates VEGF gradient between the upper and lower chambers, was used to investigate effect of $C$. nutans water extract on HUVEC-transmembrane cell migration. As shown in Fig. 5, VEGF induced HUVEC-transmembrane migration by $1.71 \pm 0.07$ fold as compared to the untreated control. However, this event was not reversed by $C$. nutans water extract, confirming the inability of $C$. nutans water extract in altering HUVEC chemotaxis in response to VEGF.

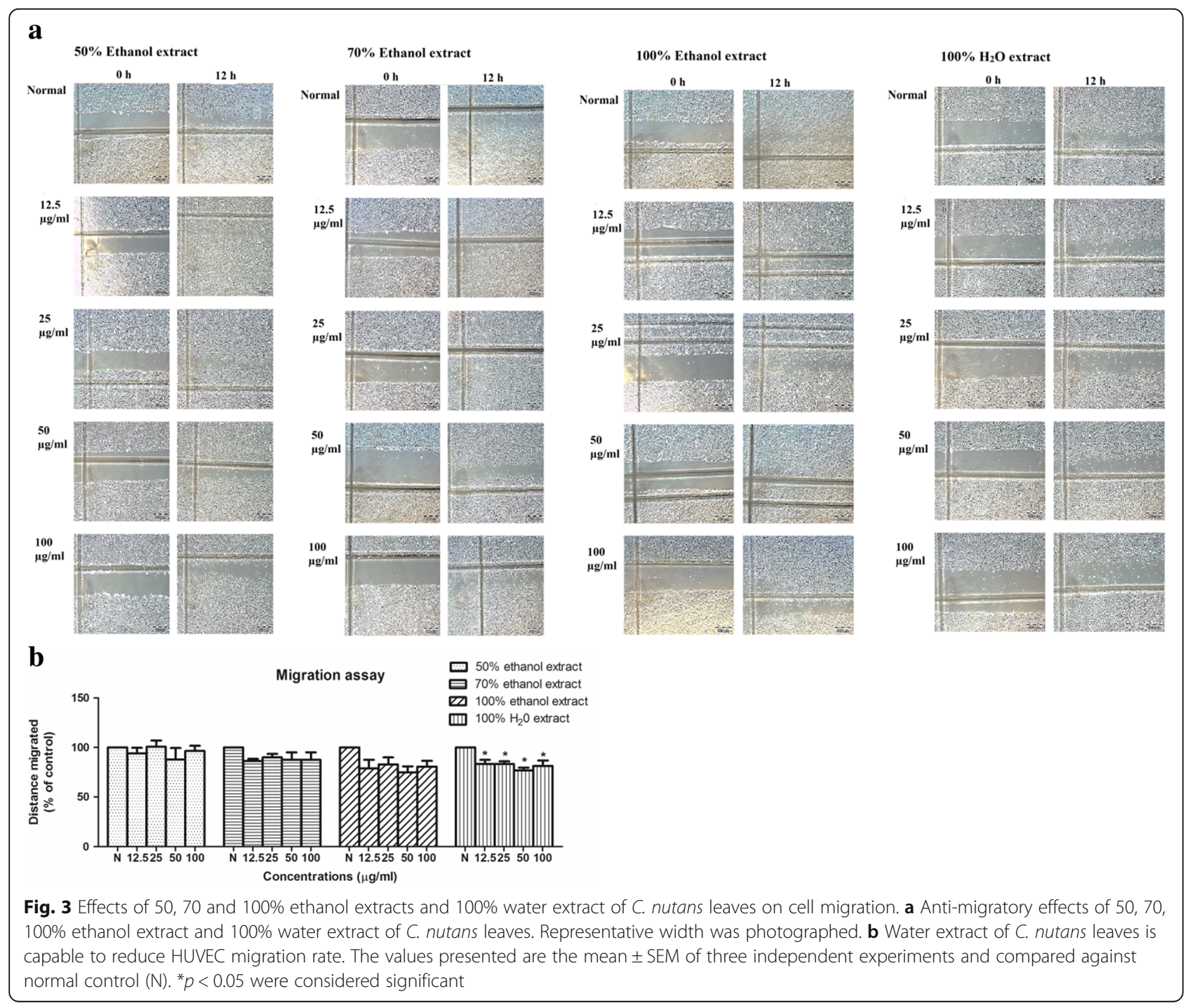




\section{a $\quad 100 \% \mathrm{H}_{2} \mathrm{O}$ extract}
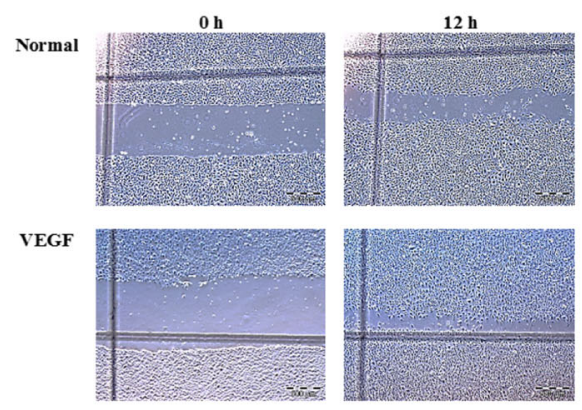

b Migration Assay $\left(100 \% \mathrm{H}_{2} \mathrm{O}\right.$ Extract)
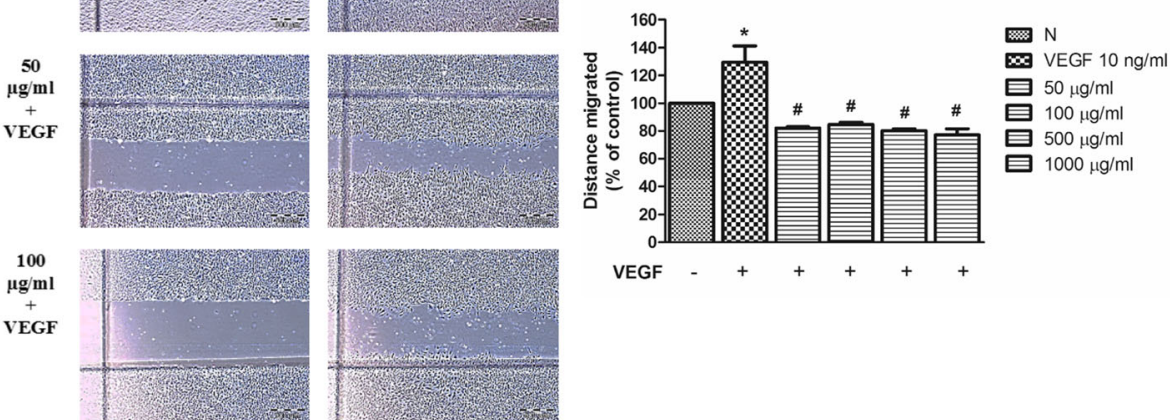

VEGF
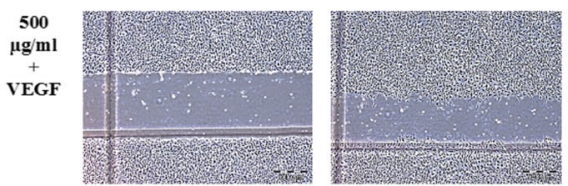

Fig. 4 Effect of C. nutans water extract on VEGF-induced cell migration. a Anti-migratory effect of 100\% water extract of C. nutans leaves. Representative width were photographed. $\mathbf{b}$ HUVECS treated with water extract of $C$. nutans leaves showed reduction in migration rate. The values presented are the mean \pm SEM of three independent experiments. ${ }^{*} p<0.05$ were considered significant when compared to normal control ( $N$ ); $\# p<0.05$ were considered significant when compared to VEGF alone group

\section{C. nutans water extract does not suppress VEGF-induced capillary tube formation}

It is known that a complex endothelial tubular network can be formed when endothelial cells were cultured in three dimensions Matrigel bed in the presence of VEGF [20], and such event can be disrupted by Suramin, a drug which is commonly used in treating sleeping sickness and river blindness [21]. Here we showed that VEGF induced HUVEC capillary tube formation in Matrigel after $3 \mathrm{~h}$, with the measured tube length of $126.30 \pm 5.64 \%$ as compared to untreated control; whereas Suramin treated-HUVECs lost its tube formation capability completely (Fig. 6). To examine if the water extract of $C$. nutans could suppress VEGF-induced endothelial tube formation, we tested the extract at high concentrations from 50 to $1000 \mu \mathrm{g} / \mathrm{ml}$. However, no suppressive effect was observed in all C. nutans treated group.

\section{C. nutans water extract increases endothelial permeability}

The endothelial permeability, measured by fluorescent unit relative to the amount of fluorescein isothiocyanate (FITC)-dextran which passes through the cell monolayer, showed that $C$. nutans water extract significantly increased endothelial permeability levels to $211.80 \pm 22.03$, $228.10 \pm 5.23,223.20 \pm 11.80$ and $226.80 \pm 43.67 \%$ when treated at 50, 100, 500 and $1000 \mu \mathrm{g} / \mathrm{ml}$, respectively (Fig. 7). VEGF was used as a reference whereby VEGF increased HUVEC permeability to $202.27 \pm 9.90 \%$ of control.

As VEGF secreted by tumor cells plays a crucial role in neoangiogenesis, we also investigate $C$. nutans water extract if it is capable of inhibiting VEGF secretion by human oral squamous cell carcinoma, HSC-4 cells [22]. Nonetheless, all doses of C. nutans water extract failed to reduce the VEGF level at $72 \mathrm{~h}$ post-treatment (data not shown). These data indicate that $C$. nutans does not attenuate VEGF production by cancer cells.

\section{C. nutans water extract suppresses VEGF-induced aortic ring sprouting and angiogenesis in CAM model}

To investigate the effect of $C$. nutans water extract on the VEGF-induced vascular sprouting, a rat aortic ring assay was performed. In the control, the non-stimulated aortic rings exhibited a sprout area of $1.14 \pm 0.09 \mathrm{~mm}^{2}$ (Fig. 8). Similar to the tube formation assay, the aortic ring sprouting effect was improved to $1.74 \pm 0.28 \mathrm{~mm}^{2}$ 


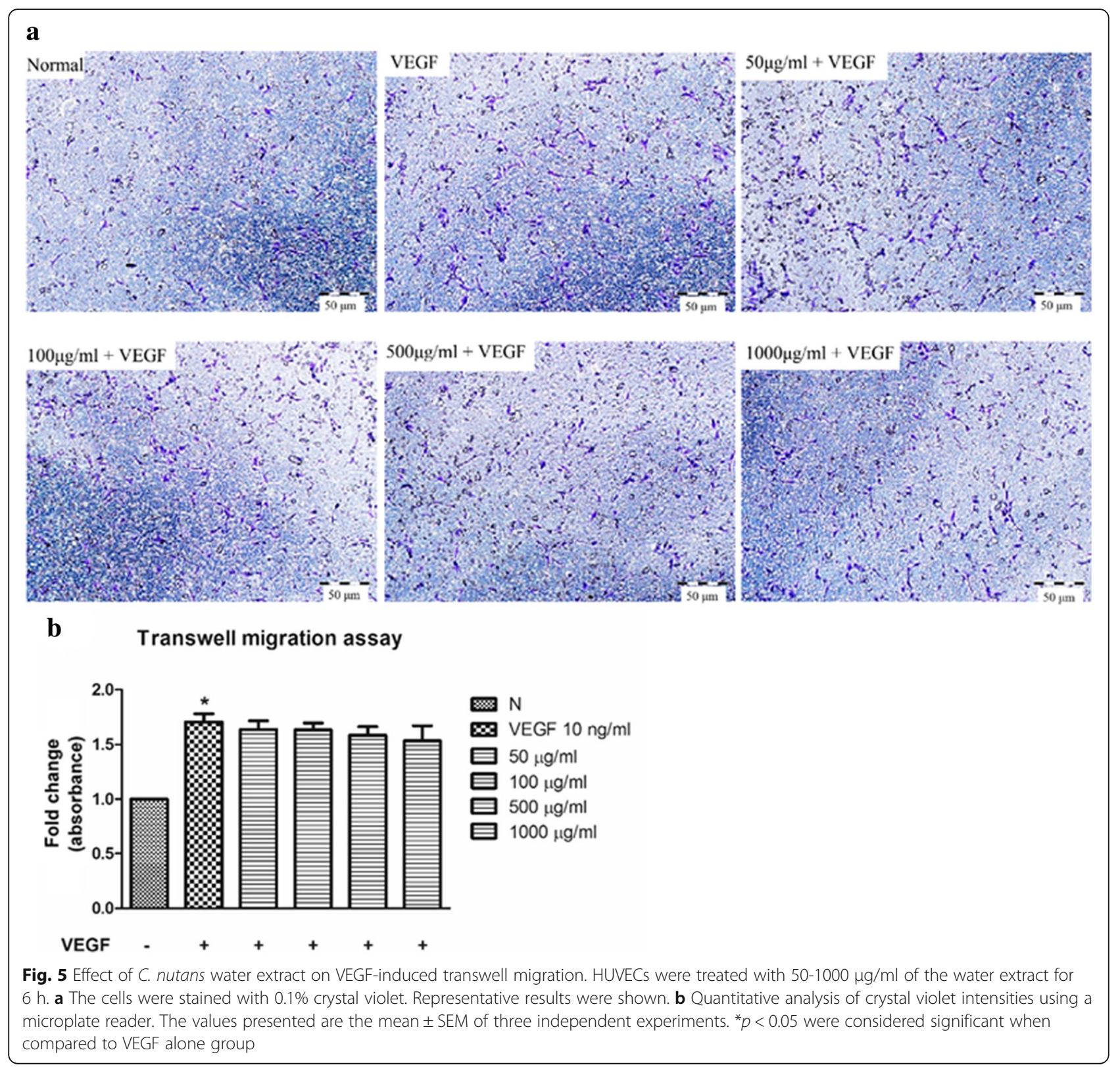

in the presence of VEGF, but was completed abolished by $50 \mu \mathrm{M}$ Suramin. When the rings were treated with 100,500 and $1000 \mu \mathrm{g} / \mathrm{ml}$ of C. nutans water extracts, sprout area was significantly reduced to $0.71 \pm 0.05,0.33$ \pm 0.03 and $0.03 \pm 0.03 \mathrm{~mm}^{2}$, respectively. These data indicate that $C$. nutans water extract inhibits vascular sprouting and fusion of neovessels ex vivo. We then tested this effect in an in vivo CAM model, and observed the similar capability in C. nutans water extract, of which successfully diminish microvessel counts to $14.90 \pm 1.40$ and $13.40 \pm 1.49$ at 1000 and $2000 \mu \mathrm{g}$ respectively, as compared to VEGF treated $(23.50 \pm 1.94)$ and water-treated control group $(15.90 \pm 1.34)$ (Fig. 9).
These results suggest that $C$. nutans water extract inhibits angiogenesis in vivo.

\section{Discussion}

Tumour angiogenesis is one the main contributing factors that promotes tumour progression. Thus, targeting the blood supply may limit its growth and progression [23]. However, simultaneous targeting of multiple aspects may be required to achieve robust antiangiogenic response. This multi-targeted effect can be achieved by using combinations of drugs, or from natural medicinal herb extracts which possess various active ingredients. C. nutans has emerged as a potential regimen for cancer 

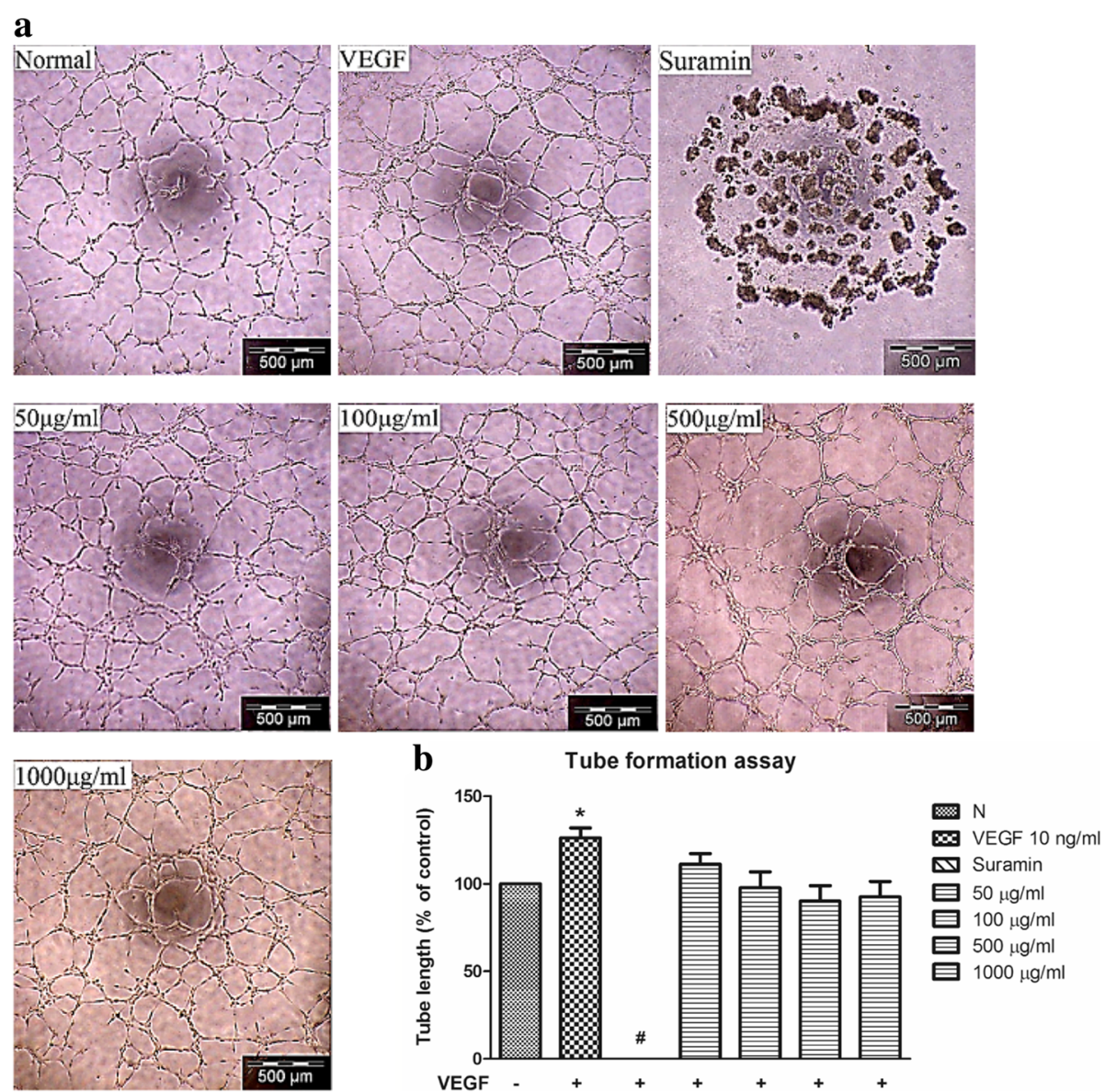

Fig. 6 Effect of C. nutans water extract on VEGF-induced capillary-like endothelial tube formation. a Microscopic examination demonstrated C. nutans extract does not suppressed VEGF-induced capillary-tube like formation in comparison with VEGF group. $\mathbf{b}$ Capillary-tube like vessel density was calculated and compared. The values presented are the mean \pm SEM of three independent experiments. ${ }^{*} p<0.05$ were considered significant when compared to normal control $(\mathrm{N})$; $\# p<0.05$ were considered significant when compared to VEGF alone group

\section{Permeability Assay $\left(100 \% \mathrm{H}_{2} \mathrm{O}\right.$ extract)}

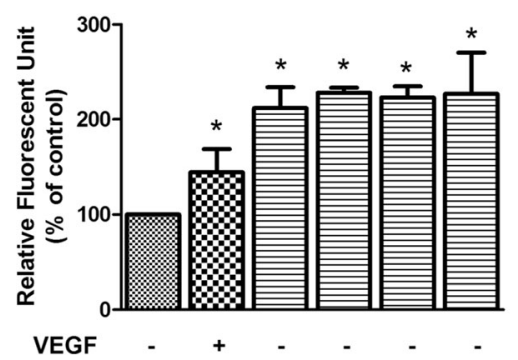

Fig. 7 Effect of $C$. nutans leaf extract on endothelial permeability. The values presented are the mean \pm SEM of three independent experiments. ${ }^{*} p<0.05$ were considered significant when compared to normal control (N) patients as accumulating lay testimonies claimed that $C$. nutans leaves capable to treat various cancer diseases [7]. Whilst more scientific evidence is needed to conclude its therapeutic use, our previous study has also shown that the $C$. nutans leaves exhibiting anti-proliferative and cytotoxicity effect against numbers of cancer cell lines [7]. Here, we demonstrated the potential of C. nutans extracts as being the antiangiogenic agent in cancer treatment.

Under physiological conditions, endothelial cell migration is coordinated by cytoskeleton reorganization where protrusions formed by lamellipodia direct the migrating cells, and this is followed by contraction of stress fibres which allows the cell body to move forward [24]. This dynamic and tightly regulated process, however, is disrupted during tumour angiogenesis, resulting in excessive cell migration and proliferation, the pivotal processes that eventually leads to structure tube and microvessel morphogenesis. In this study, we showed that these processes can be inhibited by C. nutans, 
$\mathbf{a}$
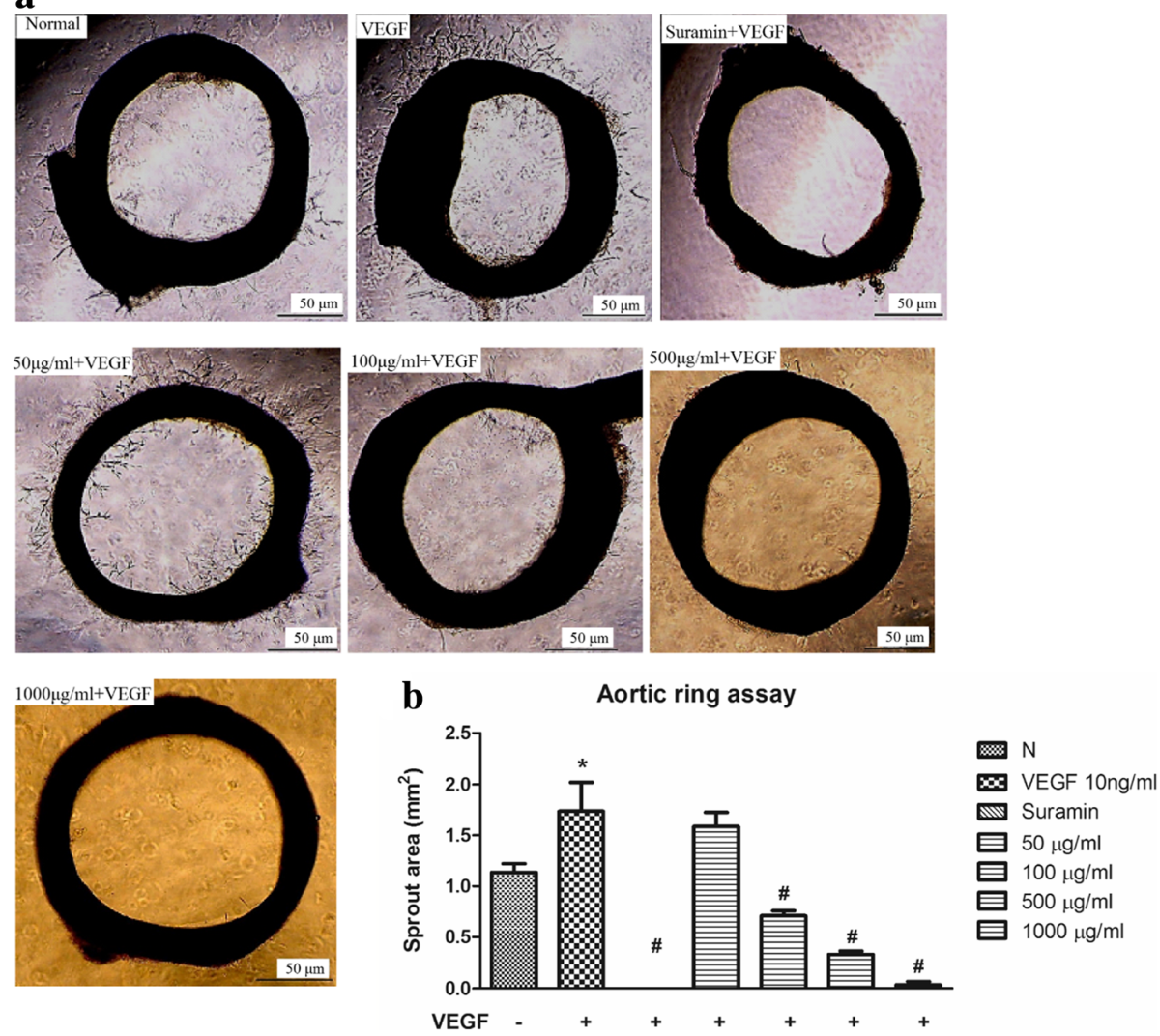

Fig. 8 Effect of $C$. nutans leaf extract on VEGF-induced microvessel sprouting of rat aortic ring. Suramin at a dose of $50 \mu M$ was used as a positive control. a C. nutans water extract inhibited vessel sprouting in rat aorta ring induced by VEGF. Representative results were shown. $\mathbf{b}$ The sprout length was quantified. The values presented are the mean \pm SEM of three independent experiments. ${ }^{*} p<0.05$ were considered significant when compared to normal control (N); \#p<0.05 were considered significant when compared to VEGF alone group. $(n=3)$

particularly the extracts from the water soluble fraction. We also tested the effect of the extracts and confirmed their efficacy even in the presence of human $\mathrm{VEGF}_{165}$, the most abundant and active isoform of VEGF-A monomer [24], which mediates angiogenesis within tumour microenvironment [25]. Taken together, our data support the notion that the water extract of $C$. nutans is capable of inhibiting VEGF-stimulated angiogenesis by targeting endothelial cell proliferation, structure tubes and microvessel formation, but not endothelial migration. Endothelial cell migration also depends on the existence of a VEGF gradient, which serves as an attractant and regulates the motion of the endothelial tip cell [19]. The Boyden chamber assay demonstrated that $C$. nutans water extract does not prevent HUVEC migration towards a chemotatic gradient, indicating that $C$. nutans does not inhibit VEGF-induced chemotaxis (Fig. 5). "Wound healing" and Boyden chamber both are type of assay to determine the migration rate of the endothelial cells, interestingly, "wound healing" assay was inhibited by the extract but Boyden chamber model failed to be inhibited by the extract. Previously reported that "wound repair" model is a multi-step process involving spreading, proliferation and migration events $[26,27]$, and our data showed that extract significantly suppressed proliferation. This again confirmed that extract inhibits "wound repair" model may via suppression of proliferation process. However, Boyden chamber model is mainly involved in migration process, thus, this indicate extracts not be able to suppress endothelial migration.

Vascular hyperpermeability is a hallmark of acute inflammation, a pathologic event that responsible for oedema and coronary heart diseases [28]. In cancers, chronic vessel hyperpermeability may facilitate leukocyte infiltration into the tumour, promote metastatic spread of cancer cells [29], and impaired efficient drug delivery due to increased interstitial pressure [30]. Drugs which capable to normalize tumour vasculature and attenuates the exaggerated permeability has emerged to be a new concept in anti-angiogenic therapy [31]. Normalization of abnormal vasculature able to increase the efficacy of conventional therapies and decrease the rate of metastasis even though it makes the vasculature to be more efficient for oxygen delivery towards the tumour [31]. 

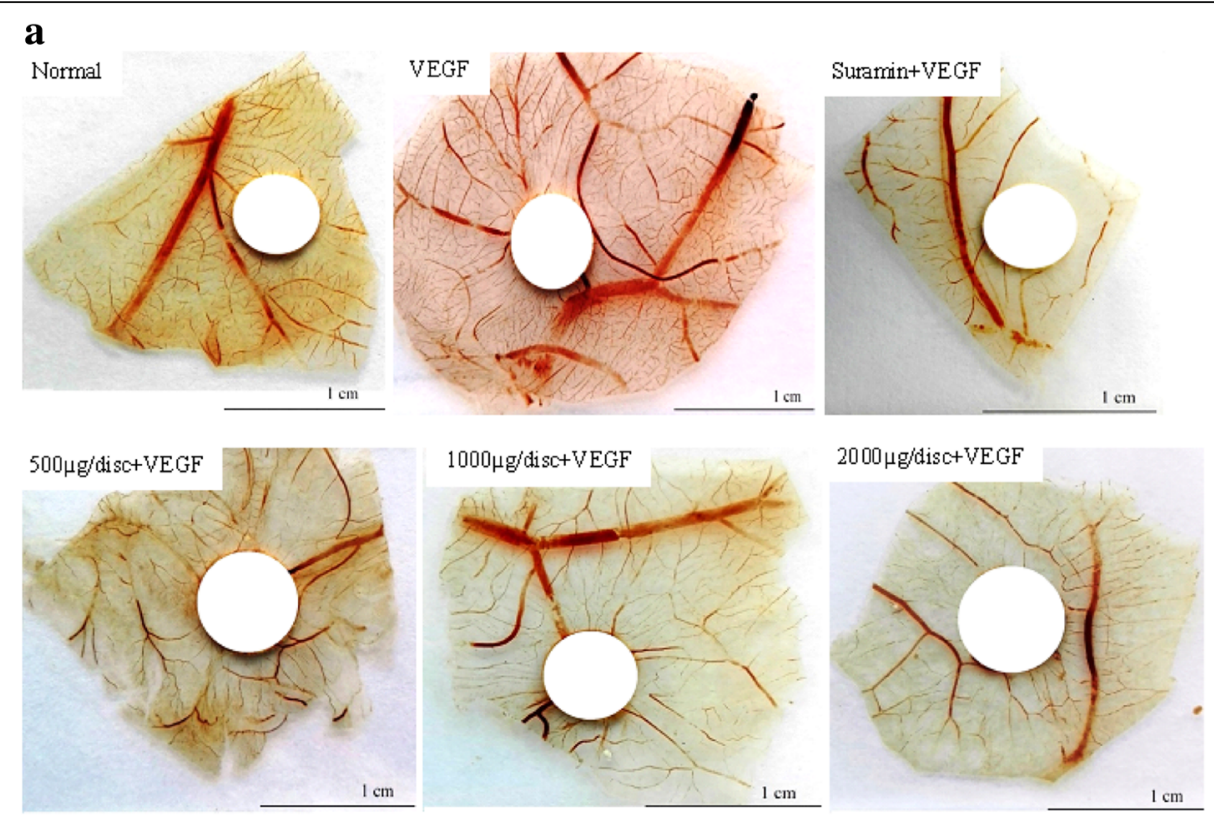

b

CAM

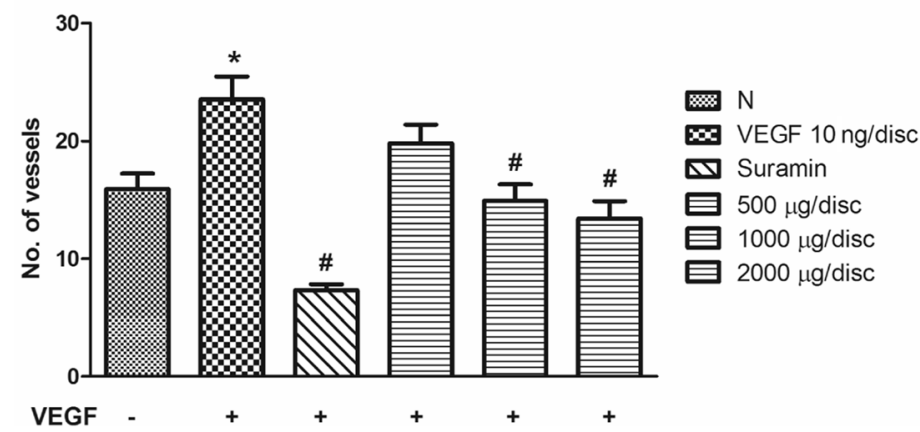

Fig. 9 Effect of C. nutans water extract on VEGF-induced angiogenesis. Suramin at a dose of $1000 \mu \mathrm{g} / \mathrm{disc}$ was used as a positive control. a C. nutans extract inhibited vessel sprouting in CAM model induced by VEGF. Representative results were shown. $\mathbf{b}$ The histogram shows the number of blood vessels contacting the discs. The values presented are the mean \pm SEM of three independent experiments. ${ }^{*} p<0.05$ were considered significant when compared to normal control (N); \#p<0.05 were considered significant when compared to VEGF alone group

Noteworthy, our findings suggest that C. nutans water extract could cause an increase in HUVEC permeability without addition of VEGF. The underlying mechanism is unknown; however, this data discouraged further study and development of $C$. nutans water extract as a potential therapeutic agent.

Apart from the cellular systems, we also examined the beneficial effects of $C$. nutans water extract using both ex vivo and in vivo models. In comparison to isolated cell culture, these models are more physiologically relevant because they allow complex cellular interactions to occur. The aortic ring assay is a type of organ culture that permits the interactions of endothelial cells with their surrounding heterotypic cells. In this assay, the endothelial cells are in a quiescent and non-proliferative state at the time of explantation. In response to pro-angiogenic agents, the cells proliferate, migrate and differentiate into tubular networks, resembling the in vivo condition [32]. In the present study, we found that C. nutans water extract significantly inhibits the microvessel outgrowth triggered by VEGF (Fig. 8), suggesting that the water extract of $C$. nutans leaves also possesses potential anti-angiogenic properties in isolated aortic tissues. The CAM model was used due to easy accessibility and highly vascularized nature of the system [33]. We demonstrated that $C$. nutans water extract prevents new blood vessel formation in the CAM model (Fig. 9). This finding is in line with the inhibitory effects of $C$. nutans on cell proliferation and migration observed in vitro, implying that the anti-angiogenic effects of $C$. nutans in HUVECs can be translated to in vivo models as well. GC-MS, chemical, ${ }^{1} \mathrm{H}$ NMR and ${ }^{13} \mathrm{C}$ NMR, HPLC with 
tandem mass spectrometry (LC/MS/MS) showed that vitexin, isovitexin and betulin [34] were among the phytochemicals that present in $C$. nutans extract which had previously demonstrated anti-angiogenesis activities [35-37]. Thus, the observed angiogenic activities in this study were likely the effect of, but not limited to, these active compounds, albeit further in-depth investigation is needed.

Number of angiogenic growth factors are known to be involved in the process of angiogenesis, this including VEGF, fibroblast growth factors, and the platelet-derived endothelial cell growth factor [38]. Binding of these angiogenic growth factors to its corresponding receptors on the surface of normal endothelial cell promote the activation of endothelial cells [39]. As a result, new blood vessels sprout from the pre-existing blood vessels. Anti-angiogenic therapies targeting various steps in this process. For instance, bevacizumab specifically binds to VEGF and thus inactivate VEGF [40]. On the other hand, Sunitinib malate has been shown to be a potent inhibitor of VEGF receptors [41]. In the current data, $C$. nutans water extract does not inhibit VEGF secretion by cancer cells. This may indicate that $C$. nutans water extract is specific to inhibit the action of VEGF on endothelial cells but not the production of VEGF from the cancer cells. Further investigation is needed in order to confirm whether $C$. nutans water extract is acting through the VEGF receptor.

\section{Conclusion}

In conclusion, we showed that $C$. nutans is capable of impeding VEGF-induced blood vessel formation by targeting on endothelial cell proliferation, aortic vessel sprouting and the growth of micro-vessels in CAM. For the first time, we demonstrate the anti-angiogenic potential of $C$. nutans in water extract and this activity may be associated with the active compounds such as vitexin, isovitexin and betulin. However, more in-depth investigations to identify the molecular target for therapeutic intervention and to evaluate the efficacy and safety of $C$. nutans water extract in diseased animal models are required to warrant translation to therapeutics for clinical use.

\section{Abbreviations}

CAM: Chorioallantoic membrane; FITC: Fluorescein isothiocyanate; HUVECs: Human umbilical vein endothelial cells; VEGF: Vascular endothelial growth factor

\section{Acknowledgements}

This study was completed in the support by the funding from NKEA Research Grant Scheme (NRGS) No.NH1014D071, Herbal Development Office (HDO), Ministry of Agriculture and Agro-based Industry, Malaysia.

\section{Funding}

Research funding from NKEA Research Grant Scheme (NRGS) No.NH1014D071, Herbal Development Office (HDO), Ministry of Agriculture and Agro-based Industry, Malaysia.

\section{Availability of data and materials}

The datasets analyzed during the current study are available from the corresponding author on reasonable request.

\section{Authors' contributions}

CTN, LYF, JJT, NFR and YKY participated in the design of the research; YKY and JJT guided the group of researchers. FA, KS and FJ contributed to plant collection, identification and extraction; CTN and LYF carried out the experiments and analysed the data under supervision of YKY. CTN and YKY wrote the paper; JJT, NFR and KMC critically revised the manuscript. All authors read and approved the final manuscript.

\section{Ethics approval and consent to participate}

The experimental protocol was established, performed in accordance with the guidelines and were approved by the Institutional Animal Care and Use Committee (IACUC), Faculty of Medicine and Health Sciences, Universiti Putra Malaysia (UPM/IACUC/AUP-R071/2015)

\section{Consent for publication}

Not applicable

\section{Competing interests}

The authors declare that they have no competing interests.

\section{Publisher's Note}

Springer Nature remains neutral with regard to jurisdictional claims in published maps and institutional affiliations.

\section{Author details}

${ }^{1}$ Physiology Unit, Faculty of Medicine, AIMST University, 08100 Bedong, Kedah, Malaysia. ${ }^{2}$ Department of Pre-clinical Sciences, Faculty of Medicine and Health Sciences, Universiti Tunku Abdul Rahman, 43000 Kajang, Selangor, Malaysia. ${ }^{3}$ Advance Medical and Dental Institute, Universiti Sains Malaysia, Penang, Malaysia. ${ }^{4}$ Faculty of Health Sciences, Universiti Kebangsaan Malaysia, 50300 Kuala Lumpur, Malaysia. ${ }^{5}$ Department of Food Science, Faculty of Food Science and Technology, Universiti Putra Malaysia, 43400 UPM Serdang, Malaysia. ${ }^{6}$ Faculty of Science, Universiti Putra Malaysia, 43400 UPM Serdang, Malaysia. ${ }^{7}$ Department of Human Anatomy, Faculty of Medicine and Health Sciences, Universiti Putra Malaysia, 43400 UPM Serdang, Selangor, Malaysia.

Received: 27 February 2018 Accepted: 25 June 2018

Published online: 06 July 2018

\section{References}

1. Shibuya M. Vascular endothelial growth factor (VEGF) and its receptor (VEGFR) signaling in angiogenesis: a crucial target for anti- and proangiogenic therapies. Genes Cancer. 2011;2:1097-105.

2. Casey SC, Amedei A, Aquilano K, Azmi AS, Benencia F, Bhakta D, et al. Cancer prevention and therapy through the modulation of the tumor microenvironment. Semin Cancer Biol. 2015;35:S199-223.

3. Wang Z, Dabrosin C, Yin X, Fuster MM, Arreola A, Rathmell WK, et al. Broad targeting of angiogenesis for cancer prevention and therapy. Semin Cancer Biol. 2015;35:S224-43.

4. Roviello G, Zanotti L, Cappelletti MR, Gobbi A, Senti C, Bottini A, et al. No advantage in survival with targeted therapies as maintenance in patients with limited and extensive-stage small cell lung cancer: a literature-based meta-analysis of randomized trials. Clin Lung Cancer. 2016;17:334-40.

5. Alam A, Ferdosh S, Ghafoor K, Hakim A, Juraimi AS, Khatib A, et al. Clinacanthus nutans: a review of the medicinal uses, pharmacology and phytochemistry. Asian Pac J Trop Med. 2016;9:402-9.

6. Teoh PL, Cheng AYF, Liau M, Lem FF, Kaling GP, Chua FN, et al. Chemical composition and cytotoxic properties of Clinacanthus nutans root extracts. Pharm Biol. 2017;55:394-401.

7. Yong YK, Tan JJ, Teh SS, Mah SH, Ee GCL, Chiong HS, et al. Clinacanthus nutans extracts are antioxidant with antiproliferative effect on cultured human cancer cell lines. Evid Based Complement Alternat Med. 2013;2013: 462751.

8. Mai CW, Yap KS, Kho MT, Ismail NH, Yusoff K, Shaari K, et al. Mechanisms underlying the anti-inflammatory effects of Clinacanthus nutans Lindau 
extracts: inhibition of cytokine production and toll-like receptor-4 activation. Front Pharmacol. 2016;7:7.

9. Huang D, Guo W, Gao J, Chen J, Olatunji JO. Clinacanthus nutans (Burm. f.) Lindau ethanol extract inhibits hepatoma in mice through upregulation of the immune response. Molecules. 2015;20:17405-28.

10. Fong SY, Piva T, Dekiwadia C, Urban S, Huynh T. Comparison of cytotoxicity between extracts of Clinacanthus nutans (Burm. f.) Lindau leaves from different locations and the induction of apoptosis by the crude methanol leaf extract in D24 human melanoma cells. BMC Complement Altern Med. 2016;16:368

11. Khoo LW, Mediani A, Zolkeflee NKZ, Leong SW, Ismail IS, Khatib A, et al. Phytochemical diversity of Clinacanthus nutans extracts and their bioactivity correlations elucidated by NMR based metabolomics. Phytochem Lett. 2015; 14:123-33.

12. Mosmann T. Rapid colorimetric assay for cellular growth and survival: application to proliferation and cytotoxicity assays. J Immunol Methods. 1983;65:55-63.

13. Kavitha CV, Agarwal C, Agarwal R, Deep G. Asiatic acid inhibits proangiogenic effects of VEGF and human gliomas in endothelial cell culture models. PLoS One. $2011 ; 6:$ e22745.

14. Arnaoutova I, Kleinman HK. In vitro angiogenesis: endothelial cell tube formation on gelled basement membrane extract. Nat Protoc. 2010;5:628-35.

15. Ng CT, Fong LY, Sulaiman MR, Moklas MAM, Yong YK, Hakim MN, et al. Interferon-gamma increases endothelial permeability by causing activation of p38 MAP kinase and actin cytoskeleton alteration. J Interf Cytokine Res. 2015:35:513-22

16. Bellacen K, Lewis EC. Aortic ring assay. J Vis Exp. 2009;33:e1564.

17. West DC, Thompson WD, Sells PG, Burbridge MF. Angiogenesis assays using chick chorioallantoic membrane. Methods Mol Med. 2001;46:107-29.

18. Simons M, Gordon E, Claesson-Welsh L. Mechanisms and regulation of endothelial VEGF receptor signalling. Nat Rev Mol Cell Biol. 2016;17:611-25.

19. Norton KA, Popel AS. Effects of endothelial cell proliferation and migration rates in a computational model of sprouting angiogenesis. Sci Rep. 2016;6:36992.

20. Des Rieux A, Ucakar B, Mupendwa BPK, Colau D, Feron O, Carmeliet P, et al. 3D systems delivering VEGF to promote angiogenesis for tissue engineering. J Control Release. 2011;150:272-8.

21. Margolles-Clark E, Jacques-Silva MC, Ganesan L, Umland O, Kenyon NS, Ricordi C, et al. Suramin inhibits the CD40-CD154 costimulatory interaction: a possible mechanism for immunosuppressive effects. Biochem Pharmacol. 2009;77:1236-45.

22. Michi Y, Morita I, Amagasa T, Murota S. Human oral squamous cell carcinoma cell lines promote angiogenesis via expression of vascular endothelial growth factor and upregulation of KDR/flk-1 expression in endothelial cells. Oral Oncol. 2000;36:81-8.

23. Linkous AG, Yazlovitskaya EM. Novel therapeutic approaches for targeting tumor angiogenesis. Anticancer Res. 2012;32:1-12.

24. Lamalice L, Le Boeuf F, Huot J. Endothelial cell migration during angiogenesis. Circ Res. 2007;100:782-94

25. Hoeben A, Landuyt B, Highley MS, Wildiers H, Van Oosterom AT, De Bruijn EA. Vascular endothelial growth factor and angiogenesis. Pharmacol Rev. 2004:56:549-80

26. Wong MK, Gotlieb Al. The reorganization of microfilaments, centrosomes, and microtubules during in vitro small wound reendothelialization. J Cell Biol. 1988;107:1777-83.

27. Coomber BL, Gotlieb Al. In vitro endothelial wound repair. Interaction of cell migration and proliferation. Arteriosclerosis. 1990;10:215-22.

28. Weis SM. Vascular permeability in cardiovascular disease and cancer. Curr Opin Hematol. 2008;15:243-9.

29. Claesson-Welsh L. Vascular permeability - the essentials. Ups J Med Sci. 2015;120:135-43.

30. Azzi S, Hebda JK, Gavard J. Vascular permeability and drug delivery in cancers. Front Oncol. 2013:3:211.

31. Jain RK. Normalization of tumor vasculature: an emerging concept in antiangiogenic therapy. Science. 2005;307:58-62.

32. Staton CA, Reed MW, Brown NJ. A critical analysis of current in vitro and in vivo angiogenesis assays. Int J Exp Pathol. 2009;90:195-221.

33. Ribatti D. Chicken chorioallantoic membrane angiogenesis model. Methods Mol Biol. 2012;843:47-57.

34. Zulkipli IN, Rajabalaya R, Idris A, Sulaiman NA, David SR. Clinacanthus nutans: a review on ethnomedical uses, chemical constituents and pharmacological properties. Pharm Biol. 2017;55:1093-113.
35. Wang J, Zheng X, Zeng G, Zhou Y, Yuan H. Purified vitexin compound 1 inhibits growth and angiogenesis through activation of $\mathrm{FOXO3a}$ by inactivation of Akt in hepatocellular carcinoma. Int J Mol Med 2014; 33:441-448.

36. Abu Bakar AR, Ripen AM, Merican AF, Mohamad SB. Enzymatic inhibitory activity of Ficus deltoidea leaf extract on matrix metalloproteinase-2, 8 and 9. Nat Prod Res. 2018; https://doi.org/10.1080/14786419.2018.1434631

37. Dehelean CA, Feflea S, Gheorgheosu D, Cimpean AM, Muntean D, Amiji $\mathrm{MM}$. Anti-angiogenic and anti-cancer evaluation of betulin nanoemulsion in chicken chorioallantoic membrane and skin carcinoma in Balb/c mice. J Biomed Nanotechnol. 2013;9:577-89.

38. Nguyen M. Angiogenic factors as tumor markers. Investig New Drugs. 1997; 15:29-37.

39. Nor JE, Christensen J, Mooney DJ, Polverini PJ. Vascular endothelial growth factor (VEGF)-mediated angiogenesis is associated with enhanced endothelial cell survival and induction of $\mathrm{Bcl}-2$ expression. Am J Pathol. 1999;154:375-84.

40. Shih T, Lindley C. Bevacizumab: an angiogenesis inhibitor for the treatment of solid malignancies. Clin Ther. 2006;28:1779-802.

41. Faivre S, Delbaldo C, Vera K, Robert C, Lozahic S, Lassau N, et al. Safety, pharmacokinetic, and antitumor activity of SU11248, a novel oral multitarget tyrosine kinase inhibitor, in patients with cancer. J Clin Oncol. 2006;24:25-35.

\section{Ready to submit your research? Choose BMC and benefit from:}

- fast, convenient online submission

- thorough peer review by experienced researchers in your field

- rapid publication on acceptance

- support for research data, including large and complex data types

- gold Open Access which fosters wider collaboration and increased citations

- maximum visibility for your research: over $100 \mathrm{M}$ website views per year

At BMC, research is always in progress.

Learn more biomedcentral.com/submissions 